\title{
Successful spontaneous breathing trial, early reintubation and mechanisms of weaning failure
}

\author{
Filippo Sanfilippo ${ }^{{ }^{*}} \mathbb{( 0}$, Paolo Murabito ${ }^{1,2}$, Valeria La Rosa ${ }^{3}$, Francesco Oliveri ${ }^{1}$ and Marinella Astuto ${ }^{1,2}$
}

(C) 2020 Springer-Verlag GmbH Germany, part of Springer Nature

\section{Dear Editor,}

We read with great interest the elegant study recently published by the group of Goudelin et al. [1] where authors studied weaning from mechanical ventilation (MV) in a population with chronic-obstructive pulmonary disease (COPD) and/or heart failure with reduced ejection fraction (HFrEF). The authors confirmed that left ventricular (LV) overloading is a key aspect of weaning-induced pulmonary oedema (WiPO). As cardiovascular dysfunction accounts for the majority of weaning failures (WiPO quoted around 60\% of failures by the largest published study) [2], the role of echocardiography is becoming prominent also in this context [3].

Weaning failure and prolonged MV are associated with longer intensive care unit stay, greater healthcare costs, increased morbidity and mortality [4]. The recent International Consensus Conference and WIND study [4] defined weaning failure as the occurrence of any of these: (a) failed spontaneous breathing trial (SBT); (b) reintubation/resumption of ventilator support within $48 \mathrm{~h}$ after extubation; or (c) death within $48 \mathrm{~h}$ after extubation. Therefore, the importance of extubation failure cannot be overemphasized and this seems rather logical as reintubation exposes patients to life-threatening complications. For these reasons, most studies on weaning from MV have included reintubation among the criteria for weaning failure (Table 1).

In this interesting study published in the journal [1], the authors showed that 47 out of 59 patients successfully

\footnotetext{
*Correspondence: filipposanfi@yahoo.it

${ }^{1}$ Department of Anaesthesia and Intensive Care, A.O.U., "PoliclinicoVittorio Emanuele" University Hospital, Catania, Italy
}

Full author information is available at the end of the article passed their first SBT, while 12 had failed. Noteworthy, four patients "passing the SBT" subsequently met the criteria of "extubation failure within $48 \mathrm{~h}$ ", but they were still analysed as "successful SBT". In light of the abovementioned international definition [4] and of the most common approach to define weaning failure, we ask the authors to provide data separating the study population in 43 patients (lasting successful SBT) vs 16 patients (12 SBT failure, 4 early reintubation).

Besides this request, we would like to applaud the authors for collecting data on all the five recently recommended parameters for the evaluation of LV diastolic dysfunction (LVDD), a very challenging task in the intensive care setting [5]. It would be interesting to investigate if the overall grading of LVDD was associated with weaning failure, since three parameters ( $E$ wave, $E / A$ ratio and tricuspid regurgitant jet velocity) were significantly different between groups, while the other two ( $e^{\prime}$ wave and $E / e^{\prime}$ ratio) were not.

Finally, the study population included a mixture of COPD and HFrEF patients [1], but they have different cardiovascular profiles on the systolic/diastolic function of both ventricles. A sub-group analysis may be very intriguing for readers as the mechanisms of weaning failure could be profoundly different. Simplifying, an increased venous return during the shift from positive to negative pressure ventilation may result in right ventricular dilatation, particularly in cases of already impaired or borderline function (likely in COPD). Similarly, weaning can be poorly tolerated by an already impaired LV (HFrEF) due to increased preload and also concomitant surge in afterload when SBT is commenced.

\section{Springer}


Table 1 Criteria adopted by studies focusing on weaning failure from mechanical ventilation

\begin{tabular}{|c|c|}
\hline First author, year, journal & Criteria for weaning failure \\
\hline Caille et al. 2010, Crit Care & Failed SBT or reintubation within $48 \mathrm{~h}$ \\
\hline Zapata et al. 2011, Intensive Care Med & Failed SBT or reintubation within $48 \mathrm{~h}$ \\
\hline Papanikolaou et al. 2011, Intensive Care Med & Failed SBT or reintubation within $48 \mathrm{~h}$ \\
\hline Gerbaud et al. 2012, Minerva Anestesiol & Failed SBT; do not report info on reintubation \\
\hline Moschietto et al. 2012, Crit Care & Failed SBT or reintubation within $48 \mathrm{~h}$ \\
\hline Thille et al. 2015, Crit Care Med & Failed SBT or reintubation within 7 days \\
\hline Konomi et al. 2016, Anaesth Intensive Care & Failed SBT or reintubation within $48 \mathrm{~h}$ \\
\hline Luo et al. 2017, BMC Pulm Med & Reintubation within $48 \mathrm{~h}$ or 7 days (in patients extubated after SBT) \\
\hline Haji et al. 2018, Crit Ultrasound J & Failed SBT, or reintubation, NIV or death within $48 \mathrm{~h}$ \\
\hline Tongyoo et al. 2018, Echocardiography & Failed SBT or reintubation within $48 \mathrm{~h}$ \\
\hline Amarja et al. 2019, Indian J Crit Care Med & Reintubation within 48 h (in patients extubated after SBT) \\
\hline Kaltsi et al. 2019, Crit Care Res Pract & Failed SBT; do not report info on reintubation \\
\hline Bedet et al. 2019, Crit Care & Failed SBT or reintubation within 7 days or death \\
\hline
\end{tabular}

NIV: non-invasive ventilation; SBT: spontaneous breathing trial

\section{Author details}

${ }^{1}$ Department of Anaesthesia and Intensive Care, A.O.U., "Policlinico-Vittorio Emanuele" University Hospital, Catania, Italy. ${ }^{2}$ Department of General Surgery and Medical-Surgical Specialties, Section of Anesthesia and Intensive Care, University of Catania, Catania, Italy. ${ }^{3}$ School of Anaesthesia and Intensive Care, University Hospital "G. Rodolico", University of Catania, Catania, Italy.

\section{Author contributions}

All the authors read and discussed the content of the article by Goudelin et al. in a journal club. FS wrote the draft with the initial idea of asking further analysis with a different criteria of classification. PM and VLR suggested to discuss also the possibility to analyse separately HFrEF and COPD. FO and MA suggested to ask also if the overall grading of LVDD was associated with weaning failure. All the authors critically revised the final draft and approved.

\section{Funding}

None.

\section{Compliance with ethical standards}

\section{Conflicts of interest}

The authors declare that they have no conflict of interest.

\section{Ethics approval}

Not applicable.

\section{Consent to participate}

Not applicable.

\section{Consent for publication}

Not applicable.

Availability of data and material (data transparency) Not applicable.

Code availability

Not applicable.

\section{Publisher's Note}

Springer Nature remains neutral with regard to jurisdictional claims in published maps and institutional affiliations.

Accepted: 3 July 2020

Published online: 13 July 2020

\section{References}

1. Goudelin M, Champy P, Amiel JB, Evrard B, Fedou AL, Daix T, Francois B, Vignon $P$ (2020) Left ventricular overloading identified by critical care echocardiography is key in weaning-induced pulmonary edema. Intensive Care Med 46:1371-1381

2. Liu J, Shen F, Teboul JL, Anguel N, Beurton A, Bezaz N, Richard C, Monnet $X$ (2016) Cardiac dysfunction induced by weaning from mechanical ventilation: incidence, risk factors, and effects of fluid removal. Crit Care 20:369

3. Vieillard-Baron A, Millington SJ, Sanfilippo F, Chew M, Diaz-Gomez J, McLean A, Pinsky MR, Pulido J, Mayo P, Fletcher N (2019) A decade of progress in critical care echocardiography: a narrative review. Intensive Care Med 45:770-788

4. Beduneau G, Pham T, Schortgen F, Piquilloud L, Zogheib E, Jonas M, Grelon F, Runge I, Nicolas T, Grange S, Barberet G, Guitard PG, Frat JP, Constan A, Chretien JM, Mancebo J, Mercat A, Richard JM, Brochard L (2017) Epidemiology of weaning outcome according to a new definition. the WIND study. Am J Respir Crit Care Med 195:772-783

5. Sanfilippo F, Scolletta S, Morelli A, Vieillard-Baron A (2018) Practical approach to diastolic dysfunction in light of the new guidelines and clinical applications in the operating room and in the intensive care. Ann Intensive Care 8:100 